\title{
The Flow of Water Past the Seven Stones Lightvessel.
}

\author{
By \\ J. N. Carruthers, D.Sc., \\ Fisheries Laboratory, Lowestoft.
}

\section{Introductory Remarks-with Brief Reference to Relevant Existing Information.}

THE purpose of this paper is to place on record the results of a series of current measurements carried out from the Seven Stones Lightvessel in August and September, 1933.

The observations are believed to be the first set of direct current measurements of any duration made in the area. The instrument employed was a Drift Indicator such as has long been in constant use at the Varne Lightvessel, and of which a full description is readily available in the popular pamphlet which appeared as No. 17 of the Ministry's series of "Fisheries Notices."

Details as to the duration and continuity of the observations to be dealt with can be gleaned from the table given below.

It may be recalled that what one learns from the employment of the instrument in question, is the residual current-or what Doodson has called the average constant current.

It is hoped before long to carry out from the Seven Stones Lightship, precisely similar continuous current observations to those which have been in train for more than eight years from the Varne Lightvessel, and the investigation below dealt with was in the nature of a preliminary experiment.

Thanks are due to the Trinity House for permission to make the observations from their lightship; to their District Superintendent concerned (Captain R. W. V. Plimsaul), to the officers of their steamer S.V. Mermaid (Messrs. J. C. McCarthy and C. E. K. Carpenter), and in particular to the Master of the lightvessel (Mr. T. Boyd) who, besides making the observations, logged the relevant wind and sea particulars,

The Seven Stones Lightship is moored at $50^{\circ} 03^{\prime} \mathrm{N} .-6^{\circ} 04^{\prime} \mathrm{W}$. in 39 fathoms of water; its position therefore is about 14 miles due west of Land's End.

The observations were made (as at the Varne) at the nominal depth of six fathoms. 
It would be of considerable interest fully to relate the results which we shall present below to prevailing ideas concerning the nature of the water movements in the Land's End-Scillies passage, to what is known of the circulation at large off the mouth of the Channel and the entrance to the Irish Sea, and also to the Rennell Current question.

Exigencies of space preclude more than a few brief remarks in these connections. The reader who is acquainted with the relevant literature will know that any adequate account presenting citations from the publications of Matthews, Harvey, Lumby, Gehrke, and others, would convey the impression that the most usual direction of water flow through the passage is towards the northern half of the compass.

Admiralty tidal stream observations relating to the position of the lightvessel itself, and to another position about $16 \frac{1}{2}$ miles away towards S. $30^{\circ}$ E., could be shown to imply the existence of a set towards the S.E. quadrant, but it is not at all easy to decide just what degree of reliance can be placed upon indications of overall water flow derived from vectoraveraging such tidal stream data.

Examination of the records sent in to the writer when the month's observing on the Seven Stones Lightvessel was finished, revealed that there had been a flow of water towards the S.E. quadrant at the depth of six fathoms - this as the resultant for the entire period of 28 days.

In a well-known paper (1) setting forth the results of a hydrodynamical study of the water movements in the area here concerned, Harvey deduced the existence of a north-going difference in velocity between the surface water and the layer at 60 -metres depth, amounting to $1 \frac{1}{2}$ miles a daythis between Land's End and the Scillies at the end of June, 1924. He declares elsewhere, that " there can be little doubt of the existence of such a residual current superimposed on the tidal streaming, and carrying water northward into the mouth of the Bristol Channel-variable in velocity and perhaps intermittent."

Harvey's deductions from his hydrodynamical study accorded well with those earlier made by Matthews from the consideration of temperature and salinity distribution, and upon which he based his conclusions as to the circulation in the area. His (Harvey's) results do not tell us what was the overall movement of the entire water column ; his values would have to be compounded with the vectors representing the movements of the water below 60 metres before we could learn that.

Harvey's stated conclusion for the Land's End-Scillies passage was that the surface water had its own proper movement of $1 \frac{1}{2}$ miles a day towards N.N.E. over the water below 60 metres - this direction of movement being declared to be suggested by the trend of the pressure contours on his chart. A glance at the latter, however, makes one suppose that "N.N.E." is a misprint for " N.N.W." 
As regards the water movements in the Irish Sea at large, it is well known that there is a residual streaming towards the north, and that it has been inferred from purely physical data that the whole body of water in the Irish Sea is changed every year, and that it passes to the north between Ireland and Scotland.

When one is considering the water movements off Land's End, one's thoughts readily turn to the Rennell Current, for if a north-going flow of water across the mouth of the Channel were the most usual state of affairs, one might reasonably expect a northerly set off Land's End to be the rule. If, however, it could be shown that the direction of water flow through the Scillies-Land's End passage is most usually southerly, there would be reason to expect that the Rennell Current can be nothing more than an occasional phenomenon, and some measure of justification for supposing Krümmel to be right when he declares that "Nach alledem wäre es endlich an der Zeit, den Rennellstrom von den Karten zu tilgen."

Events in re currents off Land's End can hardly fail to be linked up with the water movements to the south, and the driving force of the Rennell Current merits a few words. Tait has recently found that with certain pooling-up conditions in the Moray Firth due to an unusually strong inset from seawards, an escape-current can be generated, which, trending north, can head across the ocean passage north of Scotland and cut off the usual inflow.

Since the Rennell Current is held to be born of similar effects in the Bay of Biscay, may not it too be a similarly occasional phenomenon?

If it is, then we ought not to be unduly surprised if we find reason to suppose that there is most usually a S.E.-going flow through the ScilliesLand's End passage.

If the remarks made above, in conjunction with the results to be set out below, lead to further investigations designed to ascertain the most usual state of affairs, our chief aim in writing this paper will have been achieved.

\section{The Records Obtained.}

Below we tabulate the results of the 28 days' observations at the Seven Stones Lightvessel.

\section{Tidal Streams.}

Our first comment on the table can well refer to the tidal streams, since comparison between our data and those available in the Admiralty Manual (2, page 40) besides being of interest, can be very easily made.

We find that the total mileage run per tidal period of the streams in all the directions concerned can, according to the showing of our Drift Indicator, be taken as $7 \cdot 3$. This value can be regarded as a representative average. 
Residual Currents and Winds at the Seven Stones Lightvessel during a 28-day Period

Dates and Terminal Hours

Lo the
Record. Days.

of the Observation.

$0910(17.8 .33)-1000(18.8 .33)$

$1010(18.8 .33)-1100(19.8 .33)$

$1110(19.8 .33)-1200(20.8 .33)$

$1210(20.8 .33)-1300(21.8 .33)$

$1310(21.8 .33)-1400(22.8 .33)$

$1410(22.8 .33)-1500(23.8 .33)$

$1510(23.8 .33)-1600(24.8 .33)$

$1610(24.8 .33)-1700(25.8 .33)$

$1710(25.8 .33)-1800(26.8 .33)$

$1810(26.8 .33)-1900(27.8 .33)$

$1910(27.8 .33)-2000(28.8 .33)$

$2010(28.8 .33)-2100(29.8 .33)$

$2110(29.8 .33)-2340$ ( 1.9 .33$)$

2400 ( 1.9 .33$)-0230$ ( 5.9 .33$)$

0240 ( 5.9 .33$)-0510(8.9 .33)$

0525 ( 8.9.33)-0755 (11.9.33)

0805 (11.9.33)-0945 (13.9.33)

Residual Current :

Tota

Residual Current :
Sea Miles per

Lunar Day towards

Mileage
of

The same

$6.5 \quad$ S. $34^{\circ}$ E. $\quad 12.7 \quad 6.4$

3.6 S. $11^{\circ} \mathrm{E}$.

4.9 due $S$.

11.8 S. $21^{\circ} \mathrm{E}$

12.4 S. $1^{\circ} \mathrm{W}$

0.9 S. $2^{\circ} \mathrm{E}$

$9 \cdot 1$ due $\mathrm{S}$.

$3 \cdot 3$ S. $20^{\circ} \mathrm{W}$.

$11 \cdot 7$
$14 \cdot 8$

$14 \cdot 8$
$19 \cdot 2$

$19 \cdot 2$
$2 \cdot \cdot 7$

$23 \cdot 6$

$20 \cdot 5$

$3 \cdot 3$ S. $20^{\circ} \mathrm{W} . \quad 19 \cdot 3$

$3 \cdot 7$ N. $77^{\circ} \mathrm{E}$.

4.7 N. $32^{\circ}$ E.

$2 \cdot 8 \quad$ N. $64^{\circ} \mathrm{E}$.

$2 \cdot 9$ S. $79^{\circ} \mathrm{E}$.

2.8 N. $78^{\circ}$ E.

3.4 S. $68^{\circ} \mathrm{E}$.

$2 \cdot 0$ N. $4^{\circ}$ E.

1.5 N. $2^{\circ} \mathrm{W}$.

$6 \cdot 4$ N. $36^{\circ} \mathrm{W}$

$3 \cdot 2 \quad \mathrm{~S} .61^{\circ} \mathrm{W}$.

0910 (17.8.33)-1145 (15.9.33)

1.9 S. $20^{\circ}$ E.

$14 \cdot 6$
$13 \cdot 5$

$13 \cdot 3$

$8 \cdot 2$

$29 \cdot 8$

$60 \cdot 2$

$61 \cdot 2$

$32 \cdot 0$

$20 \cdot 9$

$11 \cdot 8$

* This average does not take account of the three "l's."

Residual Wind during " $\mathrm{r}$ " denote the time of the Observa- current $\begin{array}{cl}\text { tion (Based on Eight } & \text { set to right } \\ \text { Estimates per Day } & \text { of wind, and }\end{array}$ Estimates per Day of wind, and
made aboard) in Miles "1" current per Hour from a true set to left

Direction.

14.6 S. $50^{\circ} \mathrm{W} . \quad 96 \mathrm{r}$

6.5 S. $49^{\circ} \mathrm{W} . \quad 120 \mathrm{r}$

$\begin{array}{lllll}7 \cdot 4 & & 14 \cdot 0 & \text { N. } 80^{\circ} \mathrm{W} . & 80 \mathrm{r} . \\ 9.6 & \text { New on 21st } & 20 \cdot 6 & \text { N. } 70^{\circ} \mathrm{W} & 49 \mathrm{r} .\end{array}$

11.4

11.8

$11 \cdot 8$

$10 \cdot 2$
$9 \cdot 6$
$7 \cdot 3$

$7 \cdot 3$

$6 \cdot 8$

$6 \cdot 6$

First Quarter

15.2 N. $77^{\circ} \mathrm{W}$

$78 \mathrm{r}$.

$23.0 \quad$ N. $68^{\circ} \mathrm{W} . \quad 66 \mathrm{r}$

$6.2 \quad$ N. $89^{\circ} \mathrm{W} . \quad 89 \mathrm{r}$

6.7 S. $43^{\circ}$ E. $\quad 1171$

$5 \cdot 7$ S. $66^{\circ}$ E. 143 r.

5.2 S. $24^{\circ}$ E. $\quad 56 \mathrm{r}$.

$5 \cdot 3 \quad$ S. $70^{\circ} \mathrm{W} . \quad 31 \mathrm{r}$

$6.5 \quad \mathrm{~N} .57^{\circ} \mathrm{W} . \quad 45 \mathrm{l}$.

4.5 N. $56^{\circ}$ E. 1241.

Full on 4th

$8.1 \quad$ N. $77^{\circ} \mathrm{E}-107$

Last Quarter $\quad 12.9 \quad$ N. $65^{\circ}$ E. $\quad 113 \mathrm{r}$. on 11th $\quad 5.8$ N. $64^{\circ}$ E. $\quad 80 \mathrm{r}$ 4.7 N. $41^{\circ}$ E. $20 \mathrm{r}$.

1.6 N. $27^{\circ} \mathrm{W} . \quad 77$ r.* 
Now the Admiralty tidal stream data for the position of the Seven Stones Lightship show that the total to-and-fro streamings per tidal period amount to $10 \cdot 1$ miles - this being at the time of spring tides. Assuming, as seems from Warburg's manual (3, page 73) to be justifiable, that the average rate of the streams can be taken as three-quarters of their spring rate, we obtain the value $7 \cdot 5$ to compare with ours of $7 \cdot 3$. This degree of accordance is very satisfactory indeed.

Our Drift Indicator data show that the spring-stream speed as given in the Admiralty Manual must be exceeded on occasion, and that the neapstream speed can be less on occasion than that inferable $(5 \cdot 0$ miles per tidal period) from the Admiralty data.

We do not propose to set down here any further details concerning the tidal streams, save to say that the Drift Indicator records show the dominant opposing directions to be about S. by W. and N. by E.

\section{Residual Currents: Inter-Relationship Between Wind and Water Movements.}

Let us next turn to consider the residual current, which is our main concern. We see that over the whole period of 28 days there was an overall set towards S. $20^{\circ}$ E. true and of amount 1.9 miles per day. This is the quantity in which we are most interested, for, although it is an average smoothing out residual currents of varying strengths and directions, it is the quantity with which anyone making deductions from salinity distribution would unconsciously be concerned. This is so because salinity distribution would be conditioned by the integrated effects of varying sets over a considerable period.

It is seen that there was during the entire period of 28 days, a residuum of wind travelling (within a little) in the same direction as that towards which the overall transport of water at 6 fathoms depth was effected, and it is of considerable interest to note the relative magnitudes of the residual wind and water speeds concerned.

The water speed is just a little less than 5 per cent of the wind speed, and, since residual wind and residual current are here in practically the same direction, and since they refer to a period of time long enough to be significant, we can compare the result just obtained with a similar one found earlier.

The present writer in 1930 (4) advanced a relationship between speed of surface drift-bottle travel up-Channel and speed of wind. In that case the effective wind in an up-Channel direction was in question, and both bottle and air travel related to considerable periods of time. The corresponding relationship was :-

Bottle travel $=1 / 18$ th wind travel. 
The fraction $1 / 18$ th being 5.5 per cent, the two values tally very wellparticularly as the lesser one has to do with a water layer so much below the surface as 6 fathoms. Statements could be quoted to the effect that in high latitudes the rate of water drift communicated is about 2 per cent of the velocity of the wind-and 4 per cent in low latitudes. Such statements would not necessarily be in conflict with our findings, for a higher percentage would be expected to apply where residual winds and residual currents representative of considerable periods of time are in question. We here regard our numerical relationship as nothing more than an empirical one good for the area concerned. It may have some potential usefulness, though we shall greatly hesitate to invest it with any real importance until further investigations have been made to see whether such a value emerges again. Such hesitancy is very understandable when it is remembered that we have been dealing with the water movements at 6 fathoms depth. Our reason for relating the two quantities : wind speed and water flow, is the realisation that the individual records evince a large measure of change on the part of the currents with the wind-which fact leads us to suppose there to be some inter-relationship. There are certain features of the entries in our table which suggest that we are far from entitled to assume that, if we repeated the observations many times for a like term, we should find that residual wind and residual current would customarily be directed so nearly in the same direction. A mere glance at the table shows that for a short period of time, residual current at 6 fathoms depth and residual wind can be at a large angle with each other.

\section{Angle between Current and Wind.}

Inspection of the current and wind data relating to the individual records reveals much of interest. It is to be remarked that in fifteen records (i.e. in all but three) the current set at 6 fathoms depth was directed to the right of the wind. In the three cases (records Nos. 8, 13 , and 14), where the current was directed to the left of the residual wind, there had been an abrupt change of wind.

A very interesting feature indeed is that the current was directed to the right of the wind when the latter was from any one of the four quadrants, there having been a current set to the right of the wind for :-

4 cases of wind from the S.W. quadrant.

5 cases of wind from the N.W. quadrant.

4 cases of wind from the N.E. quadrant.

2 cases of wind from the S.E. quadrant.

Much space would be needed to give an adequate analysis of the data in this connection. 
Clearly from what we have seen (in re records No. 8, 13, and 14) there must elapse some time before, after a change of wind, the current can take up the direction which would accord with the new wind direction. The angle between wind and current at 6 fathoms depth may well be a more or less constant quantity for this area where a wind of persistent direction and long duration is concerned; this we do not know, but in the near future shall endeavour to ascertain. Since the observations here being considered were made at a time when very changeable wind conditions were encountered (a fact in no way to be regretted since we have found what we have found about the relation of current direction to wind direction for winds from all four quarters) it results that the angles between current and wind vary greatly-from about 140 degees down to 20 degrees.

It is to this substantial variation that we must attribute the fact that the residual current and residual wind for the entire period of 28 days are directed towards the same point of the compass-within a little. The fact that the winds varied so much in strength must have meant that the current would swing into a new direction with change of wind less quickly in some cases than in others, and this would account for some measure of the variation in the value of the angle, and would add to the likelihood that it would be smoothed out of existence in the process of averaging over a "longish" period.

As it is, the residual current for the entire period of 28 days shows some small amount of "right deviation" which the compounding of such variant vectors has not entirely smoothed out.

It is to be expected that, after many months of observation on the Seven Stones Lightship, long period means would display the existence of an angle between current and wind. What the value of that angle would be we cannot presume to guess, but are surely entitled to assume that the current would set to the right of the wind.

The angle made to the right of the residual wind by the residual current at 6 fathoms depth can of course be easily worked out as an average for the 15 individual records above tabulated. The resulting mean value is about 80 degrees.

In view of the variation displayed, we may not accept this magnitude too confidently, but one thing we can do which seems promising: we can pay attention to records Nos. 3 to 7 which relate to a period of persistent strong winds from the N.W. quadrant, and can there see that the " right deviation " varies from 49 to 89 degrees.

If the value of 80 degrees were considered to be acceptably established, we should feel disposed to assume that the layer of water at 6 fathoms depth was little above that containing the centre-of-mass of the entire body of water which the wind was able to set in motion. 
The prospect of evaluating the separation angle in the future is very attractive ; for the present we are interested to see that in only three out of the fifteen records showing right deviation was the angle less than the 45 degrees which needs no comment.

No further remarks are called for on this matter since it will receive detailed attention after more observations with the Drift Indicator from the Seven Stones Lightship have been made.

Generalisation from the Present Findings as to the Most Usual Direction of Water Flow through the Land's EndScillies Passage,

It can be seen from our table that, although the overall set during the entire 28-day period was towards the S.E. quadrant, yet actually there was just as often a set towards the north of the E.-W. line as towards the south of it-14 days in each case. There was more often a set towards the east of the N.-S. line than towards the west of it -17 days against 9 . In so far as our results, relating as they do to a time of dominant N.W.'ly winds, might be considered not representative of the most usual state of affairs, we should remark as follows :-

The most usual direction of wind being from the S.W. quadrant, we should, judging from what we have seen as to the relation between wind and current directions, expect the set to be most frequently directed towards the S.E. quadrant, and not (as seems to be the prevailing opinion) towards a northerly point.* We should expect a persistent set towards the quadrant between N.E. and N.W. only during months characterised by wind conditions from S.E. to N.E. respectively.

These findings and expectations would lead us to doubt the existence of the Rennell Current except as an intermittent phenomenon, that is to say, we should expect there to be a north-going set off the Channel mouth much less frequently than would entitle us to perpetuate the Rennell Current.

It seems abundantly clear that many more direct current-meter observations are needed before we can hold really definite ideas as to the most usual state of affairs concerning the currents off Land's End.

\section{Varne Current and Drift-bottle Particulars.}

During the first six days of the Seven Stones observations above dealt with, the Dover Straits current was heading strongly and boldly (i.e. with a fair amount of east in it) into the North Sea. Thereafter, up to

* In this connection it is of real interest to recall the implications of the Admiralty tidal stream data briefly referred to above. As we now see, the S.E.- - going set which they implied may well be-as Harvey $(5$, p. 67$)$ supposed possible-a wind drift, but a wind drift induced by S.W.'ly winds. 
September 7th, conditions of " hold-up " of the Varne current prevailed. After that the Dover Straits current was strongly reversed-this at the time when the Seven Stones current was flowing towards north and west of north.

Ten surface drift-bottles are put out each Monday from the Seven Stones Lightship. Four liberations were made during the time of the Drift Indicator observations, but as yet only one bottle (set out on September 11th) has been recovered. This was found 121 days afterwards (on January 10th, 1934) in statistical sub-rectangle UU 4g., that is on the west coast of Ireland in latitude $52^{\circ} 30^{\prime} \mathrm{N}$. approximately.

Such a recovery position is very unusual, though one or two other bottles have been recovered on the west Irish coast. The bottle would have commenced its journey at the time of our record No. 17 (see Table above) and would have got a good start towards the N.W.

\section{SUMMARY.}

A brief reference to the state of opinion concerning the water movements off S.W. England is made. Then a series of Drift Indicator records relating to 28 days of observation at 6 fathoms depth from the Seven Stones Lightvessel is presented and discussed. An overall flow of water towards the S.E. quadrant and of speed approaching 2 miles per day characterised the entire period. The residual current as worked out for the individual records, displayed considerable variation in speed and direction - setting as frequently towards the northern half of the compass as towards the southern, but more frequently towards the eastern half than towards the western half. There were pronounced changes in the wind speed and direction, and it appears as though the wind can drive the water at 6 fathoms depth towards a point to the right of its own direction, no matter from which of the four quadrants it blows.

There is good reason to suppose that the angle between the 6 fathom current direction and that of the wind in this area would almost always be greater than 45 degrees. Observations occupying 21 days yielded an average value approaching 80 degrees.

During the entire period of 28 days, an overall transport of water towards the same direction (within a few degrees) as the residual wind proper to the whole period was effected at 6 fathoms depth-the speed of the water flow being about 5 per cent of that of the wind. This result accords very closely with an earlier relationship worked out between drift-bottle travel up-Channel and wind flow up-Channel. Since the most usual direction of wind is S.W.'ly, the findings regarding the angle between wind and current are held to justify the expression of opinion that the most usual direction of water flow through the Land's End-Scillies passage 
will be towards the S.E. quadrant. This opinion is in conflict with deductions which have been made from the study of salinity and temperature observations.

The Rennell Current question is briefly considered.

\section{LIST OF REFERENCES.}

1. Harvey, H. W. "Hydrodynamics of the Waters South-East of Ireland." Journ. du Conseil, IV, No. 1, pp. 80-92, Copenhagen, 1929.

2. Tizard, T. H. "The Tides and Tidal Streams of the British Islands." 1st Edition, 1909 (Admiralty Manual).

3. Warburg, H. D. " Tides and Tidal Streams." Cambridge, 1922.

4. Carruthers, J. N. "Further Investigations upon the Water Movements in the English Channel." Journ. Mar. Biol. Assoc., N.S., XVII, pp. 241-275.

5. Harvey, H. W. "Hydrography of the English Channel." Cons. Internat., Rapp. et Proc.-Verb., XXXVII, Rapport Atlantique 1924, Copenhagen, 1925. 